\title{
JOGOS TRADICIONAIS NO CONTEXTO EDUCATIVO
}

DOI: 105902/0102830817402

Data de Submissão: 22/03/2015

Data de Aprovação: 16/07/2015

Míriam Stock Palma

miriam.palma@ufrgs.br

Universidade Federal do Rio Grande do Sul

\section{Bruna Góis Soares de Almeida}

bruninha-edf@hotmail.com

Universidade Federal do Rio Grande do Sul

\section{Vanessa Borowski Turcati}

vanesssaturcati@hotmail.com

Universidade Federal do Rio Grande do Sul

\section{Maicon Felipe Pereira Pontes}

maicon_ppontes@hotmail.com Universidade Federal do Rio Grande do Sul

RESUMO: O objetivo deste estudo é o de refletir sobre a importância do resgate dos jogos tradicionais nas aulas de educação física escolar. Para levar a cabo este estudo de revisão, foram analisadas obras de autores clássicos na área do jogo e educação, além de artigos e teses referentes ao tema. Assim, serão discutidos os elementos da cultura lúdica infantil, as relações entre jogo e educação, os aspectos sociais e culturais que têm privado crianças da vivência dos jogos e, por fim, a indicação da instituição escolar como o espaço privilegiado para o resgate dos jogos tradicionais nos diferentes contextos de aprendizagem.

Palavras-chave: Escola. Educação física. Cultura lúdica infantil. Jogos tradicionais. 


\section{Considerações iniciais}

A relação entre os termos jogo e educação tem sido alvo de inúmeras reflexões nos âmbitos escolar e pré-escolar. É bem verdade que essa relação tem-se modificado ao longo do tempo, visivelmente influenciada pelo modo como a(s) infância(s) e a(s) criança(s) têm sido concebidas em diferentes épocas pela sociedade.

Antes da Revolução Romântica ${ }^{1}$ as crianças eram vistas como seres de valor negativo, frágeis, inacabados, de pouca razão e caráter duvidoso. Nesse cenário, o seu jogo estava impregnado de um caráter de não-seriedade e, por isso, só se justificava no contexto educativo enquanto recreação, artifício pedagógico e/ ou instrumento para diagnóstico da personalidade infantil (BROUGÈRE, 1998; KISHIMOTO, 2010; SILVA, 2003). A partir do Romantismo a concepção de infância é reavaliada e considerada como uma categoria provida de características peculiares, mas, nem por isso, de menor valor; o jogo passa assim a ser ponderado como o mais rico meio de expressão da criança, a exaltação da espontaneidade infantil. Temos que essa valorização do jogo seja o reflexo da valorização da infância.

Brougère (1998), entretanto alerta para o fato de que, se nos discursos o estabelecimento da relação jogo e educação faz um certo sucesso, nem por isso as práticas pedagógicas têm-se alterado, indicando a recreação e o artifício pedagógico como os dois grandes vetores que ainda orientam essa relação. Em sintonia com essa ideia, Debortoli (1999, p.113) afirma que, pelo fato de a relação da criança com o jogo ser identificada com momentos de prazer, descompromisso e não-seriedade, nos espaços pedagógicos a brincadeira e a ludicidade, quando acontecem, têm sido utilizadas secundariamente, apenas como suporte de outras supostas aprendizagens cognitivas. E o autor complementa: "a brincadeira e a

${ }^{1}$ A Revolução Romântica ou Romantismo caracterizou-se como um movimento artístico, político e filosófico que surgiu nas últimas décadas do século XVIII na Europa e que se estendeu por grande parte do século XIX. 
ludicidade poderiam estar sendo vivenciadas e promovidas como dimensões fundamentais da formação humana".

Paralelamente a esses conflitos, atualmente há que se pensar sobre o desaparecimento da rua como o grande palco de jogos e brincadeiras infantis e sobre as consequências inerentes a esse fato. Nessa perspectiva, Neto (2001) afirma que as crianças e jovens dos nossos dias estão sujeitos a estilos de vida muito diferentes do passado, nomeadamente na capacidade de construção de repertórios lúdicos e motores, devido a uma diminuição progressiva de independência de mobilidade corporal e a um aumento progressivo de constrangimentos sociais.

Consideramos também que, na atualidade, poucos são os lugares públicos que podem ser utilizados com segurança pelas crianças e, nesse contexto, a escola se torna um espaço privilegiado para a prática das atividades lúdicas infantis, pois oferece área ampla e segura e o contato com outras crianças e adultos, favorecendo a interação entre as gerações e a troca de conhecimentos e experiências entre elas. Há que se destacar ainda a escola como o locus onde borbulham a transmissão e a transformação de fatos culturais e brota uma verdadeira cultura infantil, fato esse que não pode ser desconsiderado na medida que, conforme Pinto (2000), indubitavelmente, jogar e brincar cabem por direito e pela própria condição de vida da criança.

Vendo, ouvindo e participando dos jogos do folclore rico que temos - nos contextos de sala de aula, do recreio, das aulas de educação física - crianças de várias gerações aprenderam, ensinaram e nos legaram esses jogos, adaptando-os, de acordo com sua cultura, oportunizando-nos a reflexão sobre jogo e aprendizagem como situações complementares, e não antagônicas.

Dessa forma, o objetivo deste estudo é o de refletir sobre a importância do resgate dos jogos, nomeadamente, dos jogos tradicionais nas aulas de Educação Física na Escola Infantil e de Ensino Fundamental. Neste artigo, inicialmente serão discutidos elementos da cultura lúdica infantil, como jogo, brincadeira e brinquedo; a seguir, as relações entre jogo e educação entrarão em pauta, considerando- 
se as mudanças de concepção de infância e criança ao longo do tempo. Serão abordados ainda, aspectos sociais e culturais que, na atualidade, têm privado crianças da vivência dos jogos, nitidamente os de caráter corporal, e, por fim, a indicação da instituição escolar como o espaço privilegiado para o desenvolvimento da cultura lúdica infantil, através do resgate dos jogos tradicionais nos diferentes contextos de aprendizagem.

\section{Cultura lúdica infantil}

Os jogos fazem parte da vida humana desde os primórdios da história da humanidade (HUIZINGA, 2005), constituindo um fenômeno de fácil identificação, mas de difícil definição. Comumente, essa é uma palavra que pode ser associada a inúmeros significados: uma partida de futebol, uma brincadeira infantil, um trocadilho de palavras, ou até mesmo um embate político podem receber o nome de jogo. Essas são atividades muito distintas, que assumem diferentes significados para os que delas participam; entre umas e outras podem-se fazer analogias, encontrar algumas similaridades, peculiaridades que as aproximam ou as distanciam, mas parece muito difícil, senão impossível, distinguir um traço comum que permita a elaboração de uma definição inequívoca do termo.

A dificuldade de uma definição torna-se ainda maior, considerando que uma mesma atividade pode ser interpretada como jogo ou não jogo, dependendo do significado a ela atribuído. Um exemplo é citado por Kishimoto (2010), que diz que, quando alguém vê uma criança indígena atirando uma flecha com seu arco pode, em uma rápida observação, considerar que ela está jogando, enquanto que, para a comunidade indígena, a atividade nada mais é do que um preparo para a caça, necessária para a sobrevivência de seu povo. Essa distorção pode ocorrer até mesmo quando o professor propõe um jogo com algum fim educativo durante uma aula; provavelmente será possível notar aqueles alunos que entram no espírito do jogo e também outros tantos que percebem a proposta como um simples exercício, uma tarefa a ser cumprida, desvinculada de características 
próprias do jogo, tais como a liberdade, o prazer, o caráter improdutivo, a frivolidade. Por isso, concordamos com Brougère (1998, p.191) de que "o jogo não é um comportamento específico, mas uma situação na qual esse comportamento adquire uma significação específica" e, portanto, é preciso estar em perfeita simbiose com o jogador para identificar, em sua atitude, o verdadeiro envolvimento no jogo, a intenção lúdica.

Intimamente ligados ao jogo, há ainda dois termos que, para muitos autores, são sinônimos e, por isso, indissociáveis do jogo: brincadeira e brinquedo. É importante mencionar que jogo e brincadeira, dois termos distintos em português, são fundidos em várias outras línguas: jeu, em francês; play, em inglês; spiel, em alemão; juego, em espanhol; gioco, em italiano (HUIZINGA, 2005; BROUGÈRE, 1998). Embora não haja consenso entre os autores de língua portuguesa, via de regra eles apontam a brincadeira como uma forma mais livre que o jogo, um comportamento espontâneo que resulta de uma atividade não-estruturada e preferencialmente infantil, ou, ainda, desregrada, ao passo que associam o jogo às atividades lúdicas com regras (DANTAS, 2002; SILVA, 2003; FRIEDMANN, 1996; KNIJNIK; KNIJNIK, 2004).

Entendemos que a regra, citada na literatura como um elemento de distinção entre esses dois fenômenos - presente no jogo e ausente na brincadeira - não se constitua verdadeiramente como esse elemento; diferentemente, acreditamos que no jogo a regra é mais explicitada, enquanto que, na brincadeira, ela aparece normalmente de forma implícita e não, necessariamente, ausente. As crianças, ao brincarem de bonecas, geralmente não as põem para dormir sobre o fogão ou a banheira, e sim, sobre a cama ou o berço, incorporando, ao brincar, as regras sociais de seu contexto. Mas poderão acordar também regras diferentes. Não queremos dizer, com esse exemplo, que não haverá uma brincadeira de casinha sem regras, mas esta não é uma condição para que a brincadeira ocorra. No presente artigo adotaremos o conceito defendido pelos autores que entendem 0 jogo e a brincadeira como sinônimos. 
Além desses dois termos, o brinquedo também faz parte da cultura lúdica. Para Kishimoto (2010) o brinquedo, que é o instrumento do brincar, pode se moldar a qualquer situação. Dessa forma, uma bola pode ser usada tanto para as possibilidades que, à primeira vista, este objeto sugere aos adultos (chutar, quicar, arremessar, etc), quanto para o que a imaginação da criança permitir (uma barriga de grávida, um sol, um banquinho para sentar, etc).

O jogo, a brincadeira e o brinquedo - elementos da cultura lúdica - são reconhecidos atualmente como molas propulsoras indispensáveis para o desenvolvimento infantil saudável. Brincando, jogando, construindo, manipulando e compartilhando seus brinquedos, a criança experimenta sua capacidade de comunicação, busca soluções para os desafios impostos em seu ambiente, confronta-se com seus limites e com suas qualidades, desenvolve autonomia, liderança e competências de adaptação social, além de vivenciar experiências diversificadas, livre de preocupações relacionadas aos efeitos de suas ações.

Mas é importante destacar que, se hoje o jogo é valorizado pelos benefícios e possibilidades que traz à criança, nem sempre foi assim. Antes da Revolução Romântica, o jogo infantil era considerado não somente fútil, sem utilidade, como também nefasto, nocivo ao desenvolvimento da criança, não podendo conter, nessa lógica, um valor pedagógico em si. Essa ideia, segundo Kishimoto (2002) provém da associação do jogo infantil ao jogo de azar, a dinheiro, bastante divulgado principalmente durante a Idade Média.

\section{Jogo e educação}

O primeiro vínculo entre educação e jogo data da antiguidade greco-romana e estava alicerçado no pensamento de que o jogo era necessário, uma vez que ele permitia a reconstituição das forças dispendidas no trabalho, incluindo o trabalho escolar, e, portanto, era através do relaxamento promovido pelo jogo que um novo esforço seria possível; assim, um aluno relaxado tornar-se-ia mais eficiente em seus exercícios e em sua atenção. Mesmo sendo o jogo encarado 
como uma atividade na qual só havia desperdício de energia, deveria ser praticado com a finalidade de poder tornar mais eficaz o retorno ao estudo e ao trabalho (KISHIMOTO, 2010). Essa oposição jogo/trabalho, que se pode estender para recreação/ensino, subsiste ainda hoje e tem originado, ao longo do tempo, uma série de questões, principalmente quanto à legitimidade do jogo no contexto educativo. Afinal, algo que se oponha ao trabalho não pode ser sério, e a falta de seriedade, de utilidade, de produtividade, via de regra, não acolhem valores que pertencem ao universo da educação!

"A criança deve ter a impressão de que está jogando. É preciso enganar a criança para fazê-la trabalhar, sem que se dê conta realmente disso" (BROUGĖRE, 1998, p.55). Esse pensamento revela a segunda concepção quanto às relações entre jogo e educação: este aparece como um suporte sedutor, atrativo na educação de crianças que estão aprendendo a ler e a escrever, com o objetivo de não desencorajá-las com estudos inadequados à sua idade.

Nesta abordagem, o valor educativo está focado no conteúdo correspondente aos objetivos pedagógicos, que é definido e controlado pelo educador, mas, para despertar o interesse das crianças, o trabalho deve assumir o aspecto de jogo. Predomina visivelmente a ideia de que, sem a intervenção do adulto, nada pode levar à educação dos aprendizes. Dessa maneira, o jogo, enquanto artifício pedagógico, continua destituído de valor positivo; ele é justificado no contexto educativo somente por seu caráter aprazível.

De uma forma ou de outra, aos poucos, vai-se afirmando a relação entre criança, jogo e educação, o que incita os pedagogos a um maior interesse pelo jogo. Considerado agora também como revelador da personalidade e dos talentos infantis, torna-se um instrumento valioso a ser utilizado pelos pedagogos e psicólogos, inclusive para a adequação do ensino às necessidades dos alunos.

A partir do Romantismo nasce um pensamento científico em que a concepção de infância é reavaliada, e que dá origem a um novo olhar sobre a relação entre jogo e desenvolvimento/educação da criança. Várias teorias do jogo surgiram, 
algumas com um enfoque mais cognitivista, outras mais biológico e, especialmente entre os psicólogos da escola soviética, predominou a perspectiva social. Cada uma, sob diferentes prismas, trouxe sua contribuição para uma compreensão mais alargada do fenômeno jogo.

\section{A criança, o jogo e a escola na atualidade}

As contribuições dadas pelos estudiosos da área do jogo têm repercutido nos sistemas educacionais, despertando nos educadores o interesse quanto à apropriação do mesmo no âmbito do ensino escolar e, especialmente, no pré-escolar. Há uma consciência cada vez maior de que, nos processos de desenvolvimento e aprendizagem, a criança mobiliza componentes internos, confere significações próprias aos estímulos que lhe chegam do ambiente e age sobre eles; logo, não é mais pensada como um mero assimilador de conhecimentos, mas um ser ativo nesses processos. Nessa perspectiva, o jogo parece ser um fator que desencadeia motivações importantes para as aprendizagens e, por isso, Ribeiro (2005) acredita que retirá-lo da clandestinidade, da subversão, explicitando-o como meta da escola e não como pertencente ao seu currículo oculto, configura-se como um importante papel do professor.

Os conhecimentos adquiridos pela criança a partir da vivência dos jogos e brincadeiras praticados em casa, na rua, no centro comunitário, no clube podem e devem - ser considerados como ponto de partida para novas aprendizagens no cenário da escola. Além disso, as brincadeiras realizadas nos recreios e nos tempos livres nesta instituição não só não devem passar despercebidos pelos educadores, como também precisam ser resgatados nos contextos das aprendizagens ditas formais, como na própria sala de aula, nas aulas de educação física, de música, de artes, etc. Essas ideias vão ao encontro da de Spodek e Saracho (1998), que sugerem que os professores necessitam estar atentos às aprendizagens incidentais de seus estudantes, nomeadamente aquelas provenientes de jogos, brincadeiras e atividades desafiadoras, para maximizar novas aquisições. 
Vivemos em uma sociedade em que a instituição escolar é cada vez mais tomada como um espaço privilegiado para as experiências de jogos e brincadeiras infantis, especialmente se estivermos nos referindo às de caráter corporal. Durante muito tempo e até há algumas décadas, a rua era o grande palco de jogos e brincadeiras de crianças, jovens e adultos: reunir filhos e netos para construir e compartilhar brinquedos, bem como ensinar e aprender jogos e brincadeiras fazia parte da rotina de muitas famílias. Jogar Taco e Bola de gude, pular Amarelinha, brincar de Cinco Marias, Pega bandeira e Polícia e ladrão, equilibrar-se sobre Pés de lata, entre outros, eram momentos aguardados do dia e, com certeza, fonte de inúmeras aprendizagens e ensinamentos. Nesse contexto, os jogos configuravam-se como um rico instrumento de transmissão cultural e, ao mesmo tempo, elos entre grupos de épocas e/ou espaços diferentes, pois constituíam semelhantes maneiras de expressão desses grupos (COIMBRA, 2007; CALEGARI; PRODÓCIMO, 2006).

Tais jogos, hoje chamados tradicionais, são caracterizados pela transmissão oral, anonimato, conservação, tradicionalidade, universalidade e mudança (FRIEDMANN, 1996; KISHIMOTO, 2001). Assim, nesses jogos é possível se constatar a existência de certos padrões lúdicos universais, mesmo observandose diferenças regionais, como variações nas designações, nas regras e nas suas formas de utilização.

Vasconcellos (2008) também resgata que os jogos inicialmente eram praticados por adultos e crianças, mas com a Modernidade e a valorização do trabalho, o brincar passou a ser relacionado ao ócio, e este só era permitido às crianças, ainda que com restrições e vigilância. Embora para essa autora a criança moderna tenha recebido como herança os jogos tradicionais, acreditamos que a menor interação entre pais e filhos, netos e avós, devido à maior carga horária de trabalho dos pais/ avós, as novas formas de moradia que confinam os sujeitos em espaços cada vez menores, a oferta e a segurança reduzidas das áreas ao ar livre para a realização desses jogos, bem como a vasta e crescente oferta de jogos virtuais são fatores 
que têm feito com que os jogos tradicionais percam espaço para aqueles que não necessitam nem de interação nem de área física externa para a sua realização. Inúmeros estudos (FRIEDMANN, 1996; PALMA; PEREIRA, 2005; RANGEL; DARIDO, 2011; PEREIRA; PALMA; NÍDIO, 2009; SILVA; SAMPAIO, 2011) têm enfatizado a necessidade de a escola tomar para si a responsabilidade de resgatar a cultura infantil, através do conhecimento e da vivência dos jogos tradicionais, uma vez que as brincadeiras e jogos, nitidamente os de caráter corporal, estão perdendo um espaço precioso em nossa sociedade. Acreditamos que cabe, sim, à escola garantir, planejar e organizar espaços para maximizar o potencial lúdico infantil.

Um aspecto ainda a ser ressaltado é que, embora o jogo tradicional possua o caráter da reprodutibilidade, de geração para geração, é passível de ser transformado (a partir dos jogos já conhecidos, discutindo-os e propondo-lhes alterações com os alunos), assim como servir de referência para a criação de novos jogos (invenção de novas formas de jogar, com novos objetivos, regras, formas de organização, materiais e tempo de jogo) (RANGEL; DARIDO, 2011). Nesse sentido, Friedmann (1996) defende que os jogos tradicionais infantis deveriam se constituir um dos enfoques básicos para o desenvolvimento dos programas pré-escolares e do Ensino Fundamental, uma vez que têm qualidades que podem satisfazer às necessidades de desenvolvimento das crianças contemporâneas, nas mais diferentes esferas: física, motora, sensorial, social, afetiva, intelectual, linguística, etc.

Os estudos de Palma e Pereira (2005) e de Silva e Sampaio (2011) utilizaram como palco para esse resgate as aulas de Educação Física junto às turmas de Jardins de Infância e de anos iniciais do Ensino Fundamental, respectivamente, sendo que no primeiro estudo os próprios familiares (pais, mães, avôs, avós, tios) participaram efetivamente do ensino e até mesmo da confecção conjunta com as crianças dos jogos na instituição escolar. Pensar e implantar os jogos tradicionais como um dos conteúdos da Educação Física, seja a nível escolar ou pré-escolar, 
pode representar às crianças o mergulho em sua própria história, respeitando as particularidades de cada contexto e a cultura local.

É crucial que os educadores, e de forma especial, os professores de Educação Física, que tanto utilizam jogos em suas aulas, reflitam sobre a importância que exercem como mediadores das aprendizagens e do desenvolvimento de seus alunos e sobre as oportunidades que têm dado às suas crianças, no sentido de essas poderem ser os verdadeiros atores de sua infância, de poderem reproduzir, criar e recriar sua cultura através do jogar, construir, desconstruir e reconstruir seus brinquedos e brincadeiras.

\section{Considerações finais}

A valorização do jogo infantil esteve, ao longo do tempo, atrelada às diferentes concepções de infância e de criança vigentes. Conforme tivemos a oportunidade de demonstrar no desenvolvimento deste trabalho, atualmente a literatura tem apontado o jogo como um meio riquíssimo para a promoção do desenvolvimento infantil, o que tem suscitado e intensificado a discussão entre os educadores sobre a importância da aplicação do mesmo no contexto educativo, especialmente na Educação infantil e nos primeiros anos do Ensino Fundamental.

A cultura lúdica infantil, representada pelos jogos, brincadeiras e brinquedos das crianças, tem-se modificado drasticamente nas últimas décadas à medida que a rua foi desaparecendo como o grande cenário dos folguedos: seus jogos, prioritariamente de caráter corporal, praticados em área livre e ampla, que privilegiavam as interações sociais, foram sendo substituídos pelos que não necessitam nem de área física externa nem de interação para a sua realização, sendo, muitas vezes, virtuais. Nessa perspectiva, os autores aqui consultados fazem coro no sentido de propor a seara escolar, considerando-a como instituição educacional por excelência, como palco privilegiado para o desabrochar do potencial lúdico infantil. Realça-se, finalmente, a importância do resgate dos jogos tradicionais no cenário das aulas de Educação Física na Educação Infantil e do 
Ensino Fundamental, oportunizando às crianças o conhecimento de parte de sua história, de sua cultura.

\section{Referências}

BROUGĖRE, G. Jogo e educação. Porto Alegre: Artes Médicas, 1998.

CALEGARI, R.; PRODÓCIMO, E. Jogos populares na escola: uma proposta de aula prática. Motriz, v.12, n.2, p.133-141, 2006.

COIMBRA, A. O papel dos jogos tradicionais como actividade lúdica e educacional. 2007. 31f. Trabalho de conclusão de curso (Licenciatura em Desporto e Educação Física) - Faculdade de Desporto, Universidade do Porto, Porto, 2007.

DANTAS, H. Brincar e trabalhar. In: KISHIMOTO, T. O brincar e suas teorias. São Paulo: Pioneira Thomson Learning, 2002, p.111-121.

DEBORTOLI, J. Com olhos de crianças: a ludicidade como dimensão fundamental da construção da linguagem e da formação humana. Licere, Belo Horizonte, v. 2, n.1, p.105-117, 1999.

FRIEDMANN, A. Brincar: crescer e aprender - o resgate do jogo infantil. São Paulo: Moderna, 1996.

HUIZINGA, J. Homo ludens: o jogo como elemento da cultura. 5ed. São Paulo: Perspectiva, 2005.

KISHIMOTO, T. Jogo, brinquedo, brincadeira e a educação. 13ed. São Paulo: Cortez, 2010.

KISHIMOTO, T. Jogos infantis: o jogo, a criança e a educação. 8ed. Petrópolis: Vozes, 2001. 
KISHIMOTO, T. Froebel e a concepção de jogo infantil. In: KISHIMOTO, T. O brincar e suas teorias. São Paulo: Pioneira Thomson Learning, 2002, p.57-78.

KNIJNIK, J.; KNIJNIK, S. Sob o signo de ludens: interfaces entre brincadeira, jogo e os significados do esporte de competição. Revista Brasileira de Ciência e Movimento, Brasília, v.12, n.2, p.103-109, 2004.

NETO, C. Motricidade e jogo na infância. 3ed. Rio de Janeiro: Sprint, 2001.

PALMA, M.; PEREIRA, B. O resgate da cultura infantil: estudo em um jardim de infância no Rio Grande do Sul. Boletim da Sociedade Portuguesa de Educação Física, Lisboa, v.30/31, p. 163-175, 2005.

PEREIRA, B.; PALMA, M.; NÍDIO, A. Os jogos tradicionais infantis: o papel do brinquedo na construção do jogo. In: CONDESSA, I. (org). (Re)aprender a brincar: da especificidade à diversidade. Ponta Delgada: Ed. Universidade dos Açores, 2009, p. 103-115.

PINTO, M. A televisão no quotidiano das crianças. Porto: Edições Afrontamento, 2000.

RANGEL, I; DARIDO, S. Educacao Física na escola: implicações para a prática pedagógica. 2ed. Rio de Janeiro: Guanabara, 2011.

RIBEIRO, M. O jogo na organização curricular para deficientes mentais. In: KISHIMOTO, T. Jogo, brinquedo, brincadeira e a educação. 8ed. São Paulo: Cortez, 2005, p.133-142.

SILVA, C. O lugar do brinquedo e do jogo nas escolas especiais de educação infantil. 167 f. Tese (Doutorado em Psicologia) - Curso de Psicologia, Universidade de São Paulo, São Paulo, 2003. 
SILVA, J.; SAMPAIO, T. Jogos tradicionais: reprodução, ampliação, transformação e criação da cultura corporal do movimento. Revista Brasileira de Ciência e Movimento, v.19, n.1, p.72-86, 2011.

SPODEK, B.; SARACHO, O. Ensinando crianças de três a oito anos. Porto Alegre: Artmed, 1998.

VASCONCELOS, T. Jogos e brincadeiras no contexto escolar. In; BRASIL. Jogos e brincadeiras: desafios e descobertas. 2ed. Programa salto para o futuro. TV Escola. Ano XVIII, Boletim 07, p. 48-56, mai. 2008. 


\title{
Traditional Games in the Educational Context
}

\begin{abstract}
The purpose of this study is to reflect on the importance of reviving traditional games in physical education classes in infant school and elementary school. For carrying out this review study, classic authors' works in the field of games and education were analyzed, besides articles and PhD dissertations on this subject. Therefore, this paper will discuss the elements of children's play culture; the relations between game and education; social and cultural aspects that have deprived children of game experience; and, finally, the indication of the school institution as the privileged space for reviving traditional games in different learning contexts.
\end{abstract}

Keywords: School. Physical Education. Children's play culture. Traditional games.

\section{Juegos Tradicionales en el Contexto Educativo}

Resumen: El objetivo de este estudio es reflexionar sobre la importancia del rescate de los juegos tradicionales en las clases de Educación Física en la Escuela Infantil y Educación Primaria. Para llevar a cabo este estudio de revisión, se analizaron obras de autores clásicos en el área del juego y educación, además de artículos y tesis sobre el tema. Así, este artículo discutirá los elementos de la cultura lúdica infantil, las relaciones entre juego y educación, los aspectos sociales y culturales que han privado los niños de la vivencia de los juegos y, por fin, la indicación de la institución escolar como el espacio privilegiado para el rescate de los juegos tradicionales en los diferentes contextos de aprendizaje.

Palabras clave: Escuela. Educación Física. Cultura lúdica infantil. Juegos tradicionales. 